\title{
The Delphi method as an alternative to standard committee meetings to identify ecological issues for forest ecosystem-based management: A case study
}

\author{
by K. Waldron ${ }^{1, *}$, J.-M Lussier², N. Thiffault ${ }^{3}$, F. Bujold ${ }^{4}$, J.-C. Ruel ${ }^{1}$ and B. St-Onge ${ }^{5}$
}

\begin{abstract}
The face-to-face committee meeting is one of the most common expert consultation methods used in forest management. However, it is also laden with disadvantages, such as potential inequity in its consideration of participant opinion and the time involvement required. This led us to evaluate another expert consultation method, the Delphi method, namely by implementing it to identify ecological issues associated with second-growth boreal forests in eastern Canada. We compared this method to the committee meeting method with regard to the time investment required and the efficiency of the consultations. In all, 21 experts participated in three rounds of our implementation of the Delphi method. Subsequently, we administered an appreciation survey comparing the participants' attitudes vis-à-vis the two methods. These comparisons showed that Delphi was less time-consuming compared to a committee meeting consultation of comparable scope. Participants also considered the Delphi method to be fair and impartial, as all opinions were considered, which is frequently not the case in committee meetings. That said, participants believed that committee meetings allowed for a greater understanding of others' opinions. Overall, the application of the Delphi method was shown to be a promising way of determining forest ecosystem management issues.
\end{abstract}

Keywords: Delphi method, committee meetings, expert panel, forestry, ecosystem-based management, ecological issues determination

\section{RÉSUMÉ}

La rencontre en comité d'experts est une des méthodes de consultation d'experts les plus communes dans le domaine de laménagement forestier. Elle comporte cependant certains désavantages comme le risque d'iniquités dans la prise en compte de lopinion des participants ou les longues périodes de temps requises. Ceest ce qui nous a conduits à évaluer une autre méthode de consultation dexperts, la méthode Delphi, notamment pour identifier les enjeux écologiques de laménagement écosystémique dans les forêts boréales de seconde venue de lest du Québec (Canada). Dans cet article, nous avons donc comparé cette méthode à celle des rencontres en comité d'experts sur la base du temps requis et de l'efficacité des consultations. Parmi les 30 experts contactés, 21 ont accepté de participer aux trois tours de létude Delphi. À la fin du processus, un sondage d’appréciation a permis de comparer la perception des participants sur chacune des deux méthodes. Cette comparaison a démontré que la méthode Delphi prenait moins de temps et quelle semblait plus juste et impartiale puisqueelle tenait compte de toutes les opinions, ce qui nest pas toujours le cas lors des réunions en comité. Cependant, les participants croient que les comités ont lavantage de permettre une meilleure compréhension de lopinion des autres. En conclusion, la méthode Delphi offre des possibilités intéressantes pour établir les enjeux écologiques d’aménagement forestier écosystémique.

Mots clés : méthode Delphi, consultation d’experts, comité d'experts, foresterie, aménagement forestier écosystémique, détermination d’enjeux écologiques

\footnotetext{
${ }^{1}$ Département des sciences du bois et de la forêt, Université Laval, 2405 de la Terrasse, Québec, QC G1V 0A6, Canada; Corresponding author: Email: kaysandra.waldron.1@ulaval.ca

${ }^{2}$ Canadian Wood Fibre Centre, Natural Resources Canada, 1055 du P.E.P.S., Stn. Sainte-Foy, P.O. Box 10380, Québec, QC G1V 4C7, Canada ${ }^{3}$ Direction de la recherche forestière, Ministère des Forêts, de la Faune et des Parcs du Québec, 2700 Einstein, Québec, QC G1P 3W8, Canada

${ }^{4}$ Direction des territoires fauniques structurés et de la gestion intégrée des ressources, Ministère des Forêts, de la Faune et des Parcs du Québec, 880 Chemin Ste-Foy, Québec, QC G1S 4X4, Canada

${ }^{5}$ Département de géographie, Université du Québec à Montréal, C.P. 8888 succ. Centre-Ville, Montréal, QC H3C 3P8, Canada
} 


\section{Introduction}

With the emergence of forestry concepts such as ecosystembased management (Gauthier et al. 2009), the production of studies and reports that aim to identify potential ecological or management issues has increased worldwide (Drescher et al. 2013). The ecosystem management paradigm emerged about 25 years ago and is characterized, among other things, by being adaptive as well as capable of integrating human values, considering humans to be a part of nature (Grumbine 1994). As an example of forest ecosystem management applications, the "issues and solutions" approach that has been adopted in Quebec, Canada, serves to identify provincial and regional issues in the maintenance of forest ecosystem integrity (Grenon et al. 2010). This is commonly achieved through consultation with experts from fields relevant to forest ecology, conservation and forest management. Typically, nonexpert opinions are also considered in the process (e.g., see Box 1).

Even though expert knowledge is sometimes considered as a weak source of information, when data necessary to address issues are lacking, as is often the case in natural resources management, the use of expert knowledge can be an efficient and valuable scientific approach (Oliver 2002, Cardinall 2004, Drescher et al. 2013). Expert knowledge can be qualitative, quantitative and can complement empirical data (Day and Bobeva 2005, Drescher et al. 2013).

\section{Box 1: The Laurentian Wildlife Reserve (LWR) project expert consultation}

The Laurentian Wildlife Reserve (LWR) is an $8000 \mathrm{~km}^{2}$ region located in the balsam fir-white birch boreal forest of central Quebec (Canada). Forest stands are mainly old-growth and irregular and are affected with natural disturbances and forest management (Boucher et al. 2014). The LWR project was a pilot study conducted to evaluate the feasibility of implementing ecosystem-based management at the operational scale in Quebec. The project thus included a scientific table (expert committee), the objective of which was to at establish a list of biodiversity issues associated with the forest ecosystem management of the Reserve and to hierarchize these issues (Comité scientifique sur les enjeux de biodiversité 2010). The expert committee was formed in 2006 and was composed of 11 scientists recognized for their expertise in forest ecology or management practices. Four of these experts were associated with a university, two with the federal government and five with the provincial government. The consultation process, which used the face-to-face committee meeting method, was moderated by a scientist who was chosen on the basis of his scientific background and his capacity to lead groups (M. Leblanc, Ministère des Forêts, de la Faune et des Parcs du Québec, pers. comm.). The LWR project was also composed of a partner table, which included government agencies, forest industry representatives, native communities, recreational associations, and ecological groups. The partner table used the information provided by the scientific table to establish the ecosystem management plan (Thiffault et al. 2007).
The use of expert knowledge in ecological literature has increased significantly over the last 30 years (Drescher et al. 2013). One of the most popular expert-based methods is the face-to-face expert committee meeting. This method consists of inviting experts to attend a series of meetings that gather all of the participants around the same table. Experts are invited to express their opinions, which are discussed within the group. Typically, the decision process strives to achieve a consensus. A chair leads the meeting and a secretary writes the meeting report, which is validated by the experts. Consultations by committee meetings have some advantages, including direct interaction between participants, which facilitates collaboration. However, one of the important drawbacks associated with this method is that the opinions and ideas of extroverts tend to be favoured over those of more circumspect or introverted participants (Drescher et al. 2013).

Group meetings are also inconvenient in that they demand significant time investment from experts (Linstone and Turoff 2002). When technical constraints prevent the use of conference calls or video conferencing, experts must travel to attend meetings which involves more time and money. It can also be challenging to find a schedule that fits all participants. Finally, with the growing interest in ecosystem-based management, the number of requests to participate in expert panels in forestry is rising. However, holding such panels with the consultation committee method has proven challenging given the limited availability of qualified individuals who are willing to attend such panels. For all of these reasons, there is a need to test more effective and less time-consuming alternative methods for expert consultation in forest management.

The Delphi method emerged in the 1950s and was developed by researchers of the RAND Corporation (Martino 1993, Rowe and Wright 1999). The method structures group communication processes such that complex problems can be dealt with effectively (Linstone and Turoff 2002). For example, not only are participants given ample time to reflect about the issues at hand, but they are also given the opportunity to do so by consulting other participants' positions to previous rounds. Moreover, the Delphi method is an iterative method, meaning that the results obtained at each round are analyzed and resubmitted to the same experts. In the subsequent round, experts then review and change their answers based on other participants' comments. Iterations stop when a consensus is reached or when responses achieve a certain level of stability (Rowe and Wright 1999, Okoli and Pawlowski 2004, Drescher et al. 2013). Of course, this being the digital age, this expert consultation is generally performed by electronic mail, such that no travelling or shipping is required. Moreover, the Delphi method is anonymous in that the results obtained through the consultations are presented to the participants without reference to the names of the respondents. It also allows experts to consult collectively while avoiding some of the disadvantages associated with expert consultation in face-to-face committees (Martino 1993, Garrod and Fyall 2004, von der Gracht 2012). Finally, the method is an alternative way of analyzing complex problems or issues when model-based procedures or statistically rigorous methods are neither applicable nor available (Garrod and Fyall 2004, Masse et al. 2014).

In this study, we applied the Delphi method to a complex forestry problem, namely the identification of ecosystembased management issues related to second-growth boreal forests of eastern Quebec, Canada. Within the next few years, 
a substantial volume of wood will become available for harvest in this region covering about $40000 \mathrm{~km}^{2}$ (see Boucher et al. 2014 for a map of the study area), following regrowth of forest stands that were initially harvested 50 to 80 years ago. Forest management in this boreal region poses significant challenges, as it is characterized by a long fire cycle (Bouchard et al. 2008), which leads to a high proportion of old-growth forests that cover the landscape. Seventy percent of the stands have irregular diameter structures in the absence of harvesting (Boucher et al. 2003, De Grandpré et al. 2009). Balsam fir (Abies balsamea (L.) Mill.) tends to increase with time due to fire within stands that are dominated by black spruce (Picea mariana (Mill.) B.S.P.). These characteristics increase stand vulnerability to natural disturbances, such as windthrow (Waldron et al. 2013) and spruce budworm (Choristoneura fumiferana Clemens) outbreaks (De Grandpré et al. 2009, Bouchard and Pothier 2010). These factors contribute to the ecological characteristics and biological legacies of this boreal forest and make ecosystem-based management of secondgrowth stands a complex issue. The integration of secondgrowth forests in future management is essential, as these stands cover large areas (see Boucher et al. 2014). The identification of ecological issues related to second-growth forests is the first step of this integration. Thus, we convened an expert panel regarding issues related to ecosystem-based management of second-growth boreal forests in eastern Quebec.

Our general objective was to: 1) test the feasibility, efficiency and relevance of the Delphi method for identifying ecological issues that are associated with forest ecosystembased management; and, 2) compare the Delphi method to the expert committee meeting process using two case studies.
We compared the two methods in terms of 1) the human resources that are required, and 2) their perceived advantages and disadvantages in addressing complex forestry issues.

\section{Methods}

\section{Preliminary focus group}

As a starting point, a focus group was held in January 2014 to find potential ways to facilitate consultation and to identify the obstacles that impede the expert consultation processes. As part of the focus group, a moderator questioned five scientists with experience in expert consultation and issues determination. Experts had to enumerate, based upon their experiences with ecosystem-based management, both the positive and negative aspects of the expert consultation processes in which they had participated. Some aspects were shown to be consensual and others not. Table 1 summarizes the responses that were obtained in this focus group session.

Our analysis of the obstacles identified during the focus group exercise suggested that some barriers are better tackled with the Delphi method than with face-to-face meetings. The main disadvantages of the latter are that of having to make do with a more limited number of participants, together with the travel requirements and other pressures imposed on the experts. Indeed, the Delphi approach proves particularly useful when the problem is complex (Day and Bobeva 2005, Masse et al. 2014, Mukherjee et al. 2015), as is the case in ecosystem management of the boreal forest. The advantages of the Delphi technique冈neutrality of the process due to anonymity, cost and time efficiency, feedback iteration that increases the credibility of the final outcome冈possibly explain the increasing popularity of this method in natural resource

Table 1: Focus group results on facilitating factors and obstacles related to expert consultation processes

\begin{tabular}{|c|c|c|}
\hline Ideas & $\begin{array}{c}\text { Consensus among } \\
\text { participants }\end{array}$ & $\begin{array}{c}\text { Absence of } \\
\text { Consensus among } \\
\text { participants }\end{array}$ \\
\hline \multicolumn{3}{|l|}{ Facilitating factors } \\
\hline Creation of subcommittees working on specific questions & $\mathrm{X}$ & - \\
\hline A good moderator to lead group discussions & $\mathrm{X}$ & - \\
\hline Participants have a good knowledge of the literature & $\mathrm{X}$ & - \\
\hline Research of consensus among the experts & $\mathrm{X}$ & - \\
\hline Involvement of field experts & $\mathrm{X}$ & - \\
\hline Participants' perception regarding the importance of their contributions & $\mathrm{X}$ & - \\
\hline Recognition of the efforts which experts are making as they contribute to the study & $\mathrm{X}$ & - \\
\hline Mind map to represent the issues & $\mathrm{X}$ & - \\
\hline Workplace layout facilitating discussions & $\mathrm{X}$ & - \\
\hline Involvement of people who are willing to take on responsibilities & - & $\mathrm{X}$ \\
\hline Use of email to gather ideas to facilitate the synthesis process & - & $\mathrm{X}$ \\
\hline \multicolumn{3}{|l|}{ Obstacles } \\
\hline Participant travel & $\mathrm{X}$ & - \\
\hline Considerable effort (time and otherwise) involved for the participants and facilitator & $\mathrm{X}$ & - \\
\hline Process results in a long list of issues & $\mathrm{X}$ & - \\
\hline Volunteer participants may be hard to find & $\mathrm{X}$ & - \\
\hline Difficulty to determine the criteria to use for issues ranking & - & $\mathrm{X}$ \\
\hline $\begin{array}{l}\text { Heterogeneity of the group, i.e., participants having different expertise } \\
\text { and coming from many affiliations }\end{array}$ & - & $\mathrm{X}$ \\
\hline Disagreement on basic premises & $\mathrm{X}$ & - \\
\hline Participant replacements during the process & $\mathrm{X}$ & - \\
\hline Difficulties associated with holding a discussion in a large group & & $\mathrm{X}$ \\
\hline Pressure on the experts: too few experts for too many committees & $\mathrm{X}$ & - \\
\hline
\end{tabular}


management and conservation studies (see Oliver 2002, Dresher et al. 2013, Mukherjee et al. 2015). However, to our knowledge, our study is the first time that the Delphi method has been used for the determination issues related to ecosystem-based management of the Canadian boreal forest.

\section{The Delphi Method \\ Selection of experts}

We used depth of knowledge of the eastern boreal forest ecosystem as the main criterion for expert selection. As the study area has particular characteristics that differ from those of other forest ecosystems in Quebec (Saucier et al. 2009), experts had to be familiar with the region. We also sought to set up a heterogeneous group of experts, in other words, a group composed of experts with different perspectives on the issues, as this has been shown to produce better results than a homogenous group (Delbecq et al. 1975, Meyer and Booker 2001, Rowe and Wright 2001). We thus strove to include panelists from various areas of expertise, such as disturbance ecology, plant or animal ecology, and soils or forest resource management. Because the questions addressed were highly specific and complex, we decided to include experts only (Okoli and Pawlowski 2004), who we defined as researchers or professionals who possess essential knowledge of the ecology and/or management of eastern boreal forest of Quebec. The use of a broader definition of experts (e.g., non-professional participants) is an increasing phenomenon in Delphi studies (Hussler et al. 2011, Mukherjee et al. 2015). While we do not subscribe to this broader definition, and thus did not include non-professional participants, we did make a point of involving experts from different affiliations (university, governments and non-governmental organizations) and with different backgrounds. This allowed comparing our Delphi study to another expert-based method, the Laurentian Wildlife Reserve (hereinafter "LWR") committee meetings process (see Box 1), as the panels of both processes were comparable.

An expert can be defined as "[...] a person who has background in the subject area and is recognized by his or her peers [...]" (Meyer and Booker 2001, p. 3) and, therefore, the peer nomination technique (or reputation approach) was used. This technique consists of selecting a small number of persons who are recognized experts in the particular field of study, and ask them to select a certain number of experts. The same process is repeated with the new experts, and the process continues until no new experts are identified (Schuster et al. 1985, Crance 1987, Hess and King 2002). We acknowledge that the peer nomination technique may lead to expert selection bias, such as the nomination of people from the same school of thoughts (Dresher et al. 2013). However, we opted for this technique as the pool of potential experts in this field is small, rendering a random sampling unsuitable. Three researchers considered as experts were selected based on their fundamental contributions to the understanding of the boreal forests of eastern Quebec. These experts were asked to suggest three to five other experts. We repeated the process until no or few new experts were suggested. We thereby arrived at a list of 30 experts, of whom 20 were researchers and 10 local professionals. The experts were associated with different institutional affiliations; 14 with academic institutions, 10 with the Quebec provincial government, five with the Canadian federal government, and one with a non-governmental conservation organization.
The emails that were sent requesting participation contained: i) a description of the Delphi method; ii) a general description of the context so that the experts could assess whether they had the appropriate knowledge to participate; and, iii) the approximate length of time that would be required to participate in the study (Hasson et al. 2000, Oliver 2002, Drescher et al. 2013).

\section{Delphi study progress}

Prior to each round, the questions sent to the participants were validated by four external experts. One of these experts worked for a university and the others for a government agency. These four external experts had significant knowledge of the studied ecosystem and a general understanding of the potential issues associated with the management of second-growth forests. This validation helped to ensure that questions were clear and the estimated time required to respond was realistic.

For each round, an email was sent to the experts, providing them with information about the project (general description, objectives), the deadline, and an answer form. Questions were short and simple, to avoid ambiguity (Martino 1993, Day and Bobeva 2005). Participants who needed further clarification about the questions, and the questionnaire as a whole, were invited to contact the facilitator. We considered this important, since the clear understanding of questions becomes all the more essential in the absence of face-to-face interaction (Donohoe and Needham 2009) and since the final outcomes are related to the quality of the participant's answer. After the validation phase, questionnaires were sent by email to the respondents. Appendix A presents the questions asked in each round. After each round, a report was sent to the panelists. These reports included the results from the previous round, together with experts' arguments and comments to support their opinions. This inclusion of arguments and comments in the feedback can also be considered an advantage to other methods where feedback is limited to responses and statistical information-medians and averages (Rowe and Wright 1996). For example, experts may share the same views, but have different reasons for doing so. A method gathering arguments and comments can thus capture those nuances. Fig. 1 illustrates the general structure of our Delphi study.

However, although Delphi processes generally consume less time than face-to-face meetings, they too can reach a point where they become too elaborate. In that case, they become ineffective and risk losing panelists, who then drop out due to loss of interest (Hess and King 2002, Day and Bobeva 2005). To avoid this risk, we allowed a delay of three to four weeks for each round, and sent out three reminders during this period. Feedback (including the report) was provided within one month after receiving responses.

\section{First round:}

The first round of a classical Delphi study is generally unstructured, thus allowing participants to express their opinions about the issues that they consider important (Martino 1993, Schmidt et al. 2001, Okoli and Pawlowski 2004). The first round can be seen as a brainstorming exercise that helps structuring questionnaires for subsequent rounds. In this first round, we sent a list of 38 potential ecological issues that were related to the management of second-growth boreal 
Focus group: To ensure Delphi is an

appropriate method

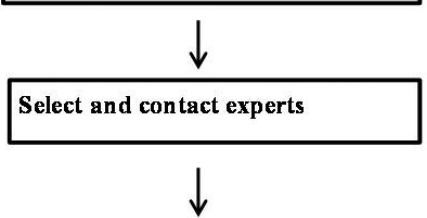

Report: Contained general information about participation rate and results from round 1
Pilot study: Questionnaire validation with four experts who were not participating in the Delphi study
Round 1: Brainstorming.

Exploration of the ecological issue related to second-growth boreal forest of eastern Quebec

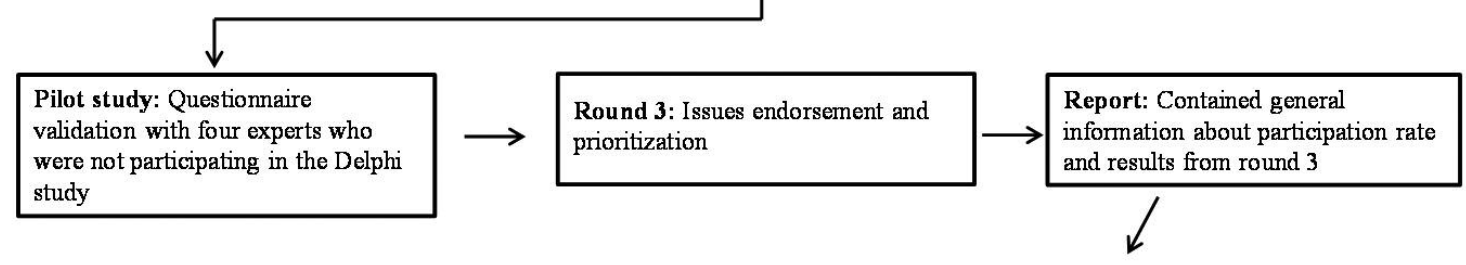

Anonymous post-Delphi survey

Fig. 1. Procedures used to conduct the Delphi study regarding ecological issues related to ecosystem-based management of the boreal forest of eastern Quebec, Canada.

forests in eastern Quebec. This list was derived from a study on ecological issues in ecosystem-based management to be considered in a forest management unit mainly characterized by primary forests, and which was close to the actual study region (F. Bujold, unpublished data, 2010). These issues were presented to the panelists using a mind map, in other words, a diagram used to simplify the organization and understanding of information. Participants had to examine the list and identify which issues should be added or dropped, and which ones should be merged. We also asked about the scale to which the issues applied (stand, landscape). We asked experts to classify the issues as either documented or as anticipated, in other words, not yet analyzed and recognized by the scientific literature. Finally, we asked participants to keep an account of the time required to complete the questionnaire. This first round aimed at contextualizing the study, and at prompting reflection on the topic.

We sent a report of the first round in which responses were consolidated to the participants. It indicated how many panelists suggested either an inclusion, exclusion or regrouping of an issue from the initial list. Justifications were also included.

\section{Second round:}

Two months after the first round, we initiated the second consultation, the aim of which was to finalize the list of issues.
Essentially, we retained all issues that were supported by at least one participant in round 1 , namely 40 , and presented those to the participants in round 2 . In this second consultation, the respondents then had to decide whether they wanted to retain or discard each of those 40 issues. We also invited them to supply justifications for their choices. Once again, participants were asked to take note of the time required to complete the questionnaire. After the second round, a new report was produced and sent to the participants. The report listed the number of participants who wanted to either keep or eliminate each of the 40 issues, together with their comments. The report also included a new list of issues that the majority of participants wanted to retain (Novakowski and Wellar 2008). In this way, the second round culminated in a final list of 29 issues.

\section{Third round:}

Five weeks after the second round, a third one was initiated. In keeping with a common practice in conducting Delphi studies (Schmidt et al. 2001, Okoli and Pawlowski 2004), the aim of this round was to rate the issues that were retained from the second round. To do so, we used a weighted voting approach: Of all the issues, the respondents were asked to select those $25 \%$ that they considered the most important. Thus, each participant had to select and prioritize seven 
issues from the list of 29 issues. The seven selected issues, in turn, were rated from 7 to 1 , with 7 denoting the highest and 1 the lowest priority. The remaining 21 issues were rated 0 . In this round as well, participants were asked to keep track of and indicate the time spent on providing their answers.

We used a weighting matrix to compile the results. The final score of each issue was calculated as the sum of the individual scores multiplied by the occurrence of individual scores $>0$. This approach, inspired from the "Borda count" voting system (Emerson 2013), has the advantage of favouring options supported by a broad consensus among experts, rather than being limited to the options that are the favourites of a majority. As was the case for other rounds, we sent a report to the participants with general information and results.

As expert participation declined with each new round, and as participant responses displayed increasing stability (Hasson et al. 2000, Day and Bobeva 2005), the Delphi process terminated after three rounds (Novakowski and Wellar 2008). Answers were considered stable between the second and the last round, since none of the issues with the highest ranks in round 3 had wanted to be removed by more than two participants in round 2.

Comparison of the Delphi and expert committee meeting methods The determination of management issues in Quebec is currently through face-to-face committee meetings, which are documented in detail. For our study, we make us of information from one such process-the Laurentian Wildlife Reserve (LWR; see Box 1) - using this as a case study.

To reach our research objectives, we conducted two exercises. First, we compared the time invested for the two consultation methods. Second, we asked the Delphi study participants to answer an appreciation survey (Novakowski and Wellar 2008) comparing the Delphi method to the expert committee meetings and other expert-based methods.

\section{Time investment}

From the meeting reports of the LWR, we obtained information about the number of experts involved and the time required for the consultation. We then compare this information with the Delphi study. In the Delphi study, participants kept an account of the time required to answer the questionnaire at each round; they were also informed that that information would be used to compare the Delphi method to another expert consultation method.

\section{Appreciation survey}

We used an appreciation survey to assess the efficacy of the Delphi method in capturing the experts' opinions and in building a common understanding. We asked the participants to rate, on a five-point Likert-scale (Lozano et al. 2008), methods according to four statements. These levels were 1) strongly disagree, 2) disagree, 3) neutral, 4) agree, and 5) strongly agree. Participants could also indicate that they either did not know or had no opinion (value of " 0 "). The statements that participants had to rate were:
1) The method allows opinions to be expressed easily;

2) The method is clear (process clarity); and,

3) The method allows every participant to give opinions equally (process fairness).

The choice of these three statements was justified by the fact that these criteria evaluate participation processes (see Conley and Moote 2003, Frame et al. 2004). In addition, the results from the focus group conducted prior to the Delphi process identified these points as being the main advantages or disadvantages associated with expert-consultation processes (see Table 1).

Finally, respondents answered three open questions to complete the evaluation of the methods. This aimed to highlight the strengths and weaknesses associated with these two methods and to see what could be improved in future expert consultation processes:

1) What do you like about each method?

2) What do you dislike about each method?

3) How would you improve the method?

\section{Results}

\section{Participation level}

Of the 30 invited experts, 21 accepted the invitation to participate in the study. These 21 experts had different institutional affiliations (Fig. 2). Of the 21 participants, 14 responded to at least one round (Table 2) and seven experts failed to respond to any round, without giving any explanation. Of the latter, five were researchers associated with a university and two were local professionals working for the provincial government. For the first round, 13 of the 21 experts answered the questionnaire, corresponding to a participation level of $62 \%$. For the second as well as third, and final, round, 11 of the 21 participating experts answered the questionnaire, corresponding to a response level of $52 \%$.

\section{Time invested by participants}

For the Delphi method, the average time taken by each participant to complete the entire exercise was 2.6 hours, with 4 hours being the most time any one participant spent on the

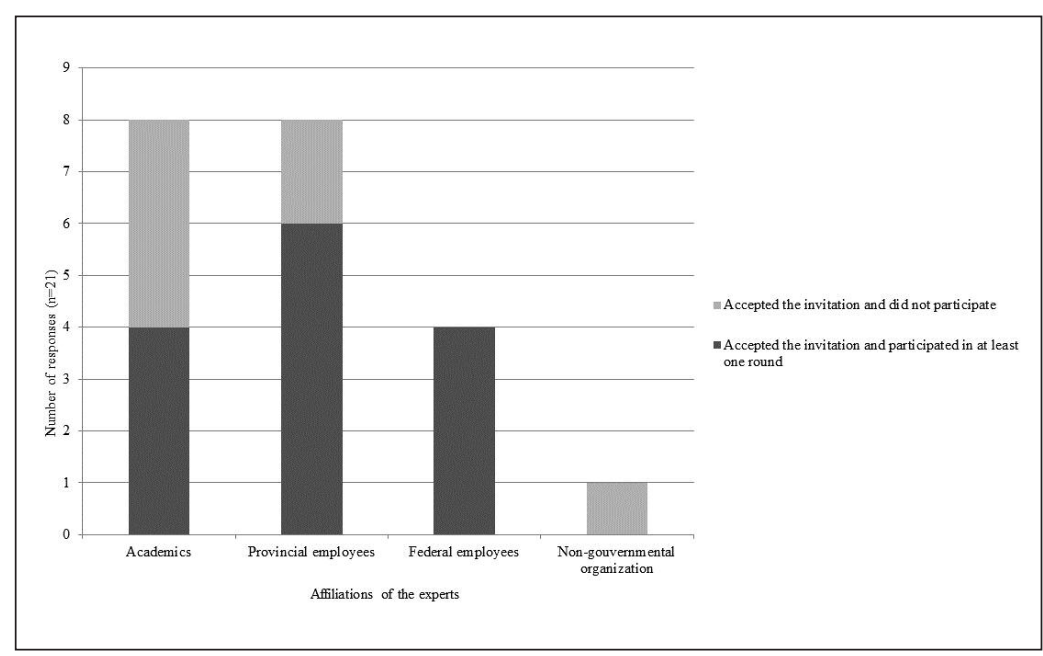

Fig. 2. Number of experts who accepted the invitation and participated, and those who accepted the invitation and did not participate. 
Table 2: Participation repartition for each round of the Delphi study and expert's affiliation.

\begin{tabular}{llccc}
\hline $\begin{array}{l}\text { Partici- } \\
\text { pants }\end{array}$ & Affiliation & $\begin{array}{c}\text { Round } \\
\mathbf{1}\end{array}$ & $\begin{array}{c}\text { Round } \\
\mathbf{2}\end{array}$ & $\begin{array}{c}\text { Round } \\
\mathbf{3}\end{array}$ \\
\hline 1 & Quebec government & $\mathrm{X}$ & $\mathrm{X}$ & $\mathrm{X}$ \\
2 & Quebec government & $\mathrm{X}$ & - & $\mathrm{X}$ \\
3 & Academic & $\mathrm{X}$ & $\mathrm{X}$ & - \\
4 & Canadian government & $\mathrm{X}$ & - & $\mathrm{X}$ \\
5 & Canadian government & $\mathrm{X}$ & $\mathrm{X}$ & - \\
6 & Canadian government & $\mathrm{X}$ & - & - \\
7 & Quebec government & $\mathrm{X}$ & $\mathrm{X}$ & $\mathrm{X}$ \\
8 & Academic & - & $\mathrm{X}$ & $\mathrm{X}$ \\
9 & Academic & $\mathrm{X}$ & $\mathrm{X}$ & $\mathrm{X}$ \\
10 & Quebec government & $\mathrm{X}$ & $\mathrm{X}$ & $\mathrm{X}$ \\
11 & Academic & $\mathrm{X}$ & $\mathrm{X}$ & $\mathrm{X}$ \\
12 & Quebec government & $\mathrm{X}$ & $\mathrm{X}$ & $\mathrm{X}$ \\
13 & Canadian government & $\mathrm{X}$ & $\mathrm{X}$ & $\mathrm{X}$ \\
14 & Quebec government & $\mathrm{X}$ & $\mathrm{X}$ & $\mathrm{X}$ \\
\hline
\end{tabular}

tations was 26.6 and 313.5 person-hours, respectively (Tables 3 and 4). Thus, the order of magnitude of the time spent in participating in the Delphi consultation was much smaller than that of the committee meetings of the LWR process.

\section{Appreciation survey}

The appreciation survey was sent by email 10 days after the end of the third round. Following a reminder email, five participants returned the survey. Of these five participants, three were affiliated with government agencies and two with a university. For four of those five respondents, the Delphi study was their first experience with this method. The remaining respondent had participated in more than five Delphi studies. Three respondents had already participated in one or more consultations conducted as committee meetings.

The first statement-"The method allows opinions to be easily expressed"- -was either agreed or strongly agreed with by the same number of participants in the Delphi study as in the committee meetings. One person thought that the Delphi method did not permit an easy expression of opinions. Almost the same scenario was observed for the statement "The method is clear." As for the statement: "The method allows every participant to give opinions equally (process equity)", all participants from the Delphi study agreed or strongly agreed with it, whereas from the committee meetings, one person agreed, two were neutral, and one person disagreed. A weighting was given to responses

Table 4: Duration and number of participants for each committee meeting of the Laurentian Wildlife Reserve (LWR) project. For more details, see Box 1.

\begin{tabular}{lcc}
\hline Date of meeting & $\begin{array}{c}\text { Meeting } \\
\text { duration (h) }\end{array}$ & $\begin{array}{c}\text { Number of } \\
\text { participants }\end{array}$ \\
\hline September 20, 2006 & 2.5 & 9 \\
October 18, 2006 & 6.0 & 9 \\
November 7, 2006 & 5.75 & 9 \\
November 20, 2006 & 5.75 & 9 \\
December 13, 2006 & 5.5 & 9 \\
March 15, 2007 & 5.5 & 9 \\
May 10, 2007 & 5.75 & 6 \\
\hline
\end{tabular}

exercise. The longest round was the first one, with an average of 1.38 hours taken to answer the questionnaire (range: 0.33 hrs to $2.5 \mathrm{hrs}$ ). The shortest round was the third round, which all participants completed in less than one hour (Table 3). By contrast, in the consultation by committee meetings, participants who attended all the meetings (in this case seven) spent a total of 36.75 hours. This time excludes transportation and preparation time. The shortest meeting (the first one) lasted $2.5 \mathrm{hrs}$ and the longest $6 \mathrm{hrs}$ (Table 4 ).

In the Delphi study, the second and third rounds had fewer participants than the respective previous one (Table 2). In contrast, the number of participants remained stable for most of the LWR committee meetings, except for the last one. The total amount of time invested by the Delphi and LWR consul- (between 0 and 5) and Fig. 3 represents this weight's distribution among the Delphi, the committee meeting and other consultation methods.

The possibility to have direct interaction with other participants was considered to be one of the positive aspects of committee meetings (Table 5). Inversely, lack of direct interaction, alongside the impossibility of knowing whether everyone had the same understanding of the issues and the procedure of the method, were perceived as the main limitations of the Delphi method. For the committee meetings, participants confirmed that it was too time-consuming and that people who had difficulties expressing themselves were at a disadvantage (Table 6). Lastly, respondents of the appreciation survey offered suggestions for improvement of the Delphi method, one being that the method should allow filtering ideas using a rule other than simple majority, and that it should address only one issue at a time to achieve a greater focus and rigour. Suggestions for improvement for the committee meeting method revolved mainly around promoting more brainstorming prior to meetings and to introducing mechanisms allowing greater equitability regarding the expression of opinions (Table 7).

\section{Discussion}

\section{Participation rate}

The Delphi method allows consulting a larger group of experts than does the committee meeting method. Facilitation methods and the use of electronic survey tools potentially allow 


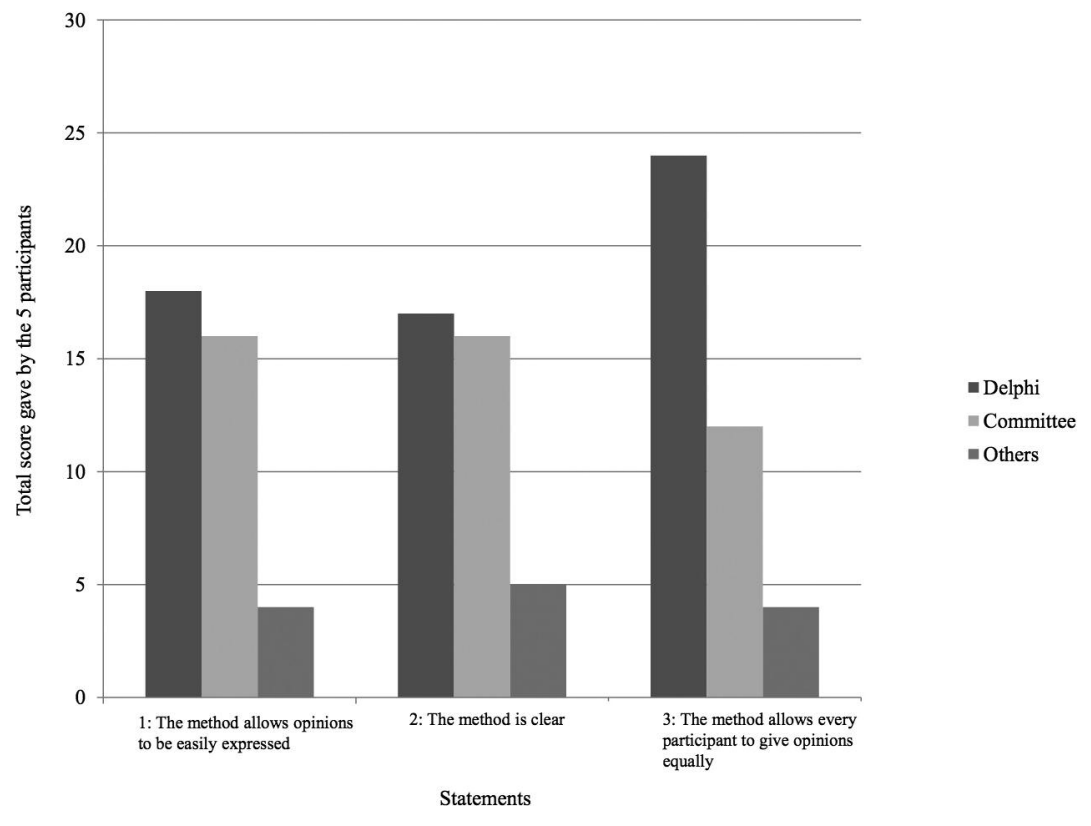

Fig. 3. Total score given for each statement by the appreciation survey participants for the Delphi technique, the committee meetings or other methods of expert consultation.

reaching a larger base of participants, which in turn can be favourable with respect to the representativeness and equitability of the amassed opinions and expertise. The number of experts involved in a Delphi study should be large enough to compensate for potential dropouts during the process. Unfortunately, experts in specific fields are not always numerous. Yet there is no consensus as to what constitutes a suitable size for an expert panel in the Delphi process (Kaynak et al. 1994, Donohoe and Needham 2009 Drescher et al. 2013). Some have argued that sample size has no or little influence if it remains stable throughout the process and if the panel is wellbalanced in terms of the backgrounds of its participants (Garrod and Fyall 2004). Others insist on the importance of having a large number of panelists (Hasson et al. 2000), whereby large groups are also associated with having a potential for inducing conflict or information overload (Rowe and Wright 2001). The scope of the problem to be addressed and the availability of experts are among the factors that should be taken into account when determining the appropriate sample size (Donohoe and Needham 2009). The number of participating experts also can be justifiably limited in studies drawing primarily on local knowledge, as was the case in our study. Some authors have argued that in a Delphi study the number of participants is less important than the diversity of expert opinions being offered, which ensures that all aspects of a given issue is being considered (Novakowski and Wellar 2008).

There is no consensus about what is an acceptable attrition rate in a Delphi process (Mullen 2003). In the present study, the participation rates ranged from $52 \%$ to $62 \%$, which is comparable to those found in some studies using Delphi to evaluate issues related to natural resources management (Hess and King 2002, Khadka and Vacik 2012). A potential problem with panel attrition is the biased results that could be obtained if the remaining participants were unbalanced in terms of background and expertise (Garrod and Fyall 2004, Dresher et al. 2013). Fortunately, in our study, the panel balance (the composition of the panel in terms of academics vs government scientists) remained stable until the end of the process despite a relatively high attrition rate.

Participants were sent only one reminder to take part in the appreciation survey, unlike the three Delphi rounds, where more reminders were sent out. Maybe more reminders would have been useful to increase the response rate, since multiple follow-up has been identified as an effective retention strategy (Robinson et al. 2007). This low participation rate for this last step in the process is surprising since attrition rates tend to be higher in the initial round (Bardecki 1984). The low participation rate for the appreciation survey could also be attributed to the fact that the survey was sent out quite soon after the last Delphi round, contrasting the longer delays between the three rounds that participants were used to.

Appreciation survey and comparison between the Delphi process and the committee meetings

The comparison between the consultation by committee meetings for the LWR project and our Delphi study is descriptive. We acknowledge that we present a case study based on a limited set of evidence. Moreover, the consultation processes which we refer to were conducted four years apart, in different regions and with different groups of experts and facilitators. However, the objectives and scope of the LWR process were comparable to those of the Delphi case. Indeed, the Delphi study and the LWR committee meetings shared a similar management context in many respects. Their forest disturbance dynamics, stand characteristics and potential ecological issues associated with forest management are all comparable. For both the Delphi study and LWR committee meetings, participants were also volunteers, their expertise was comparable, and they were affiliated with universities and government institutions. That said, these similarities would not necessarily exist when comparing two other examples of how these methods have been implemented. Instead, the comparison should be viewed as a case study of two singular, concrete situations. Moreover, the two processes examined in our study differed with regard to their social and economic contexts, with the LWR process involving more stakeholders than the Delphi process. This difference could affect the strength of the comparison, even if our analysis focussed solely on ecological issues and not on social/economic aspects. Overall, our case studies thus pro- 
Table 5: Participant perception of advantages of the Delphi method and the committee meetings respectively. Numbers in parentheses correspond to the number of participants who gave this response.

\section{Delphi}

- Speed (2)

- Participants have flexibility in choosing the time and day when they complete the survey (2)

- Confidentiality (1)

- All opinions are considered (1)

- No travelling required (1)

- Possibility to give opinions without being interrupted by others, which likely allows for a greater diversity of ideas (1)

\section{Consultation by committee meetings}

- Possibility to interact directly with others and ensure that everyone has the same understanding of the problem (2)

- Better understanding of others' opinions (1)

- Opportunity to interact directly with other participants; hence, opportunity to articulate ideas (1)

- Allows rapid and complete synthesis, and rapid verbal input of what would otherwise have taken a long time to write (1)

- Likely the most rigorous method (1)

Table 6: Participant perceptions of the limitations of the Delphi method and the committee meetings respectively. Numbers in parentheses correspond to the number of participants who gave this response.

Delphi

- Lack of direct interaction or feedback during the analysis of complex data (2)

- Not known whether others shared the same understanding of the questions (1)

- There is a moderator, who filters and categorizes interventions according to his or her own perceptions (1)

- Poor understanding of the instructions or study objectives may lead to erroneous answers (1)

- Lack of rigour: Expert opinions are given, but one expert cannot be an expert for all questions (1)
Consultation by committee meetings

- Time required (including preparation, travelling) (2)

- Discussions sometimes lead nowhere (1)

- Ideas proposed by people who have difficulty expressing themselves are less likely to be considered (1)

- Some people may avoid expressing ideas that run counter to current trends (1)

- Discussion frequently monopolized by one or a few persons (1)

- Long discussions, which occasionally lead to dead-ends (1)

Table 7: Participant suggestions for improvements to the Delphi method and the committee meetings respectively. Numbers in parentheses correspond to the number of participants who gave this response.

\begin{tabular}{|c|c|c|}
\hline Delphi & Consultation by committee meetings & Other \\
\hline $\begin{array}{l}\text { - Regrouping issues efficiently and filtering ideas } \\
\text { withrules other than the majority rule (1) } \\
\text { - Clear instructions are very important, as is } \\
\text { context description (1) } \\
\text { To improve rigour, the method could be applied } \\
\text { to precise issues (e.g., consultation of water quality } \\
\text { experts with only for a water quality issue) (1) }\end{array}$ & $\begin{array}{l}\text { - Do brainstorming before meetings (1) } \\
\text { - Integrate a mechanism that could allow every } \\
\text { participant to express himself } \\
\text { (e.g., a voting system) (1) } \\
\text { - Travelling is the longest. The use of web interfaces } \\
\text { could facilitate the holding of meetings (1) } \\
\text { - Write precise and short reports that are based on } \\
\text { the most important facts (1) }\end{array}$ & $\begin{array}{l}\text { - A mixture } \\
\text { of methods } \\
\text { could be } \\
\text { used (1) }\end{array}$ \\
\hline
\end{tabular}

vide useful information regarding the strengths and weaknesses of both methods; nonetheless, we can neither extrapolate nor generalize our results.

The amount of time required to participate in the Delphi consultation was of an order of magnitude smaller than that of consultations based on committee meetings. The speed at which the Delphi process led to a consensus was identified by two participants in our appreciation survey as a significant advantage over other consultation methods. Inversely, the considerable amount of time required to participate in committee meetings was seen as a main disadvantage of this method. In addition, in committee meetings the individual personalities of the experts can influence the length of the meetings. For example, just one very vocal expert can draw out a meeting for all participants. In that context, the skills of the chair in facilitating the dialog and consensus-building of such meetings are of utmost importance.

In ecosystem-based management, the aim is to find answers to complex problems, and this complexity warrants giving participants time to engage in lengthier thinking processes. Yet the context of face-to-face committee meetings is not conducive to in-depth reflection, functioning rather as an arena where participants are challenged to perform, assert themselves and decide quickly. With the Delphi method, by contrast, participants can decide how much time they wish to invest, and the time taken by one individual does not influence the time invested by others. Thus, a person who needs more time can proceed at their own pace without being subjected to peer pressure (Garrod and Fyall 2004). In our implementation of the Delphi method, we also made a point of keeping the questionnaires short and of allowing participants to take up to a month to answer in order to reduce time pressure to a minimum. We did ask them to keep track of the time invested in the process, although specified that this information would be used for purposes of comparison with another study only. We therefore have no reason to believe that partic- 
ipants were pressured to answer the questionnaire as quickly as possible.

The entire process spanned over about four months for the Delphi study and over eight months for the committee meetings. The LWR expert consultation process was further characterized by some degree of expert demobilization (Comité scientifique sur les enjeux de biodiversité 2010). As a general rule, long consultation processes should be avoided regardless of which method is being used (Hess and King 2002). The Delphi study was a short-term project and our results suggest that participants appeared to appreciate this aspect of the process. In a context where experts are frequently solicited to participate in different studies or committees, the time factor is a notable constraint. Our study suggests that the Delphi method is a good way of dealing with the time issue, while maintaining a high degree of involvement by the experts who are being consulted.

Our qualitative evaluation of participant views regarding the clarity of the process and its equitability likewise suggests that the Delphi method was, overall, preferred over the committee meeting method. However, in the appreciation survey, one participant mentioned that committee meetings allow for a better understanding of the opinions of others because of direct interactions. Similarly, participants mentioned that the Delphi method can lead to divergent understandings of similar problems and that it suffers from a lack of interaction among participants. In this study, we tried to circumvent this drawback by including participant comments and justifications in the reports (Rowe and Wright 1996) and by performing a questionnaire validation before each round (Donohoe and Needham 2009). Nevertheless, we anticipated that electronic means of communication would be less appreciated than face-to-face interaction by some respondents (Drescher et al. 2013).

The facilitator plays an important role in Delphi studies and contributes to the success of the process (Martino 1993, Keeney et al. 2006). Mukherjee et al. (2015) suggest that the main skills necessary for a Delphi study facilitator is impartiality, credibility, knowledge of the subject, and analytical and organizational skills. Indeed, it is within the power of a facilitator to manipulate results, an element that could discredit the method (Martino 1993). In this study, all comments were provided in the reports, as well as the raw data (before the weighting or scoring process), to ensure transparency. After each round, results and reports were verified by the same four experts who pre-tested the questionnaires.

As mentioned, facilitator skills are also important for the committee meeting process. Communication and planning skills are essential to ensure the success of such a consultation. A good facilitator is capable of leading a group and encourages all participants, whether shy or assertive, to express themselves (McFadzean and Nelson 1998, McFadzean 2002). In the LWR project, the facilitator was chosen because of his known capacity to lead a group and his scientific experience (M. Leblanc, Ministère des Forêts, de la Faune et des Parcs, pers. comm.). The fact that the two case studies discussed here were facilitated by two different people and involved different participants prevents formal comparisons. It is also difficult to dissociate the results of the appreciation surveys administered for both methods from the facilitation process itself.

Based on the appreciation survey, the respondents consid- ered that the Delphi method allowed for more equitability among experts than the committee meeting. For example, some comments included: "Possibility of giving opinions without being interrupted," "greater idea diversity," and "my opinion was considered." In the Delphi method, participants are likely to express themselves on every question and issue, which is not necessarily the case in face-to-face committee meetings. The Delphi method allows experts from different backgrounds, and thus with potentially divergent opinions, to be accommodated without judgement. In this way, it is potentially more inclusive than are committee meetings (MacMillan and Marshall 2005). Respondents to the appreciation survey indicated that the Delphi method provided greater representativeness of group opinions than did committee meetings. In a Delphi study, all participants are invited to give their opinions, so it is not surprising that the resulting reports are representative of everyone. A respondent to the appreciation survey mentioned that committee meetings have the disadvantage of promoting the ideas of leaders, or of people having greater facility in expressing themselves, which is a well-known disadvantage of this consultation method (Martino 1993, Turoff 2002).

Another respondent noted that the Delphi method lacks rigour, as participants are not experts regarding each question or issue of the study. This potential problem of the Delphi method has often been highlighted (Garrod and Fyall 2004, Hasson and Keeney 2011, Drescher et al. 2013). The Delphi method is considered rigorous if some conditions are met not only during the expert selection process but also during the elicitation process (Donohoe and Needham 2009, Drescher et al. 2013). In this regard, our case study could be criticized with respect to its selection process. Experts were recruited from among "professional" scientists, who worked in academia, government and NGOs. Indeed, as we wanted to compare the Delphi process to the common expert-based consultation method used in forest management (being the expert committee meetings), we decided to limit our definition of "experts." This decision was justified, among other factors, by the fact that the ecological issues associated with secondgrowth boreal forest are highly specific. Non-professional "citizen" scientists from local natural science clubs (amateur ornithologists, mycologists) may well have very valuable and grassroots-based knowledge of the ecosystems under study; nonetheless, we did not consider them a priori. First Nations also were not included in the process, despite their deep and long-held knowledge of the forest environment and their increasing participation in the management of Canadian forests (Wyatt 2008). We now recognize that these groups of experts should be included in consultation processes examining biodiversity issues and ecosystem integrity. Indeed, the opinions of the experts consulted in our Delphi study are not necessarily representative of the opinion of a broader population. One way to include such opinion could be to organize a face-to-face workshop with the Delphi participants and the local community members to review and question results from the Delphi study (Endter-Wada et al. 1998). One respondent to the appreciation survey also suggested that the Delphi approach could be mixed with other expert knowledge-based methods.

Yet another participant mentioned that the Delphi consultation process lacks clear focus in that its questions are too 
broad and general. Instead, the method should limit itself to one distinct issue. While we can appreciate the thoughts behind this person's comments, we stand by our decision in our application the Delphi method, in that it was our explicit focus to explore a complex reality and to favour systemthinking (Garrod and Fyall 2004, Okoli and Pawlowski 2004). It is for these same reasons that we designed our questionnaires to be broad and open, giving participants the opportunity to express themselves freely and in their own terms about the issues in question (Frewer et al. 2011, see Appendix A). Representation bias was avoided, but the Delphi method does not result in incontestable facts; rather, it represents a collective expert opinion for a specific situation at a particular time (Hasson and Keeney 2011). If the same questions were submitted to another group of experts, it is not certain that the same answers would be obtained (Hasson et al. 2000). However, this reliability issue (or the "snapshot effect") associated with expert knowledge is not exclusive to the Delphi method. In fact, it holds true for all expert-based methods (Meyer and Booker 2001).

\section{Conclusions}

In this case study, ecological issues that were associated with a complex ecosystem-based management situation were determined using the Delphi method. This method was chosen to avoid some of the drawbacks associated with the results obtained from the usual expert consultations held in the form of committee meetings. Following the Delphi study, an appreciation survey was sent to participants. Despite a low survey participation rate, the general appreciation of the Delphi method was high. According to respondents, the main advantages of Delphi are its capacity to allow substantial time saving, facilitate the sharing of opinions, and allow a greater fairness and representativeness by giving a voice to every participant. However, the method is considered to lack the interactions that favour consensus and a common understanding of issues.

Results from our case study suggest that the Delphi method is a promising expert consultation method for the field of forest management. It has several significant advantages, in particular in contexts where experts are frequently solicited. Further studies should be conducted to confirm the general applicability of the method to such contexts. As a complement to other expert-based methods or empirical data sources, the Delphi method could also become a means to identify ecosystem management issues. Nonetheless, the Delphi method is associated with several biases and limitations, such as the selection of experts, the participation rate and, increasingly, the exclusion of non-expert citizens.

\section{Acknowledgements}

This study was funded by FRQNT (Fonds de recherche du Québec-Nature et technologies). We thank all of the experts who were consulted during the Delphi process. We also thank Louis Bélanger, Marc Leblanc and Frank Grenon for their involvement in the focus group, Flor de María Robles Barreto for their helpful advice, and William F.J. Parsons and Cathleen Poehler for the English language revision. We are also indebted to Nancy Gélinas, who provided insightful comments on an earlier version of the manuscript.

\section{References}

Bardecki, M. J. 1984. Participants' response to the Delphi method: An attitudinal perspective. Technol. Forecast. Soc. 25(3): 281-292. doi: 10.1016/0040-1625(84)90006-4.

Bouchard, M., D. Pothier and S. Gauthier. 2008. Fire return intervals and tree species succession in the North Shore region of eastern Quebec. Can. J. Forest Res. 38: 1621-1633. doi: 10.1139/X07-201.

Bouchard, M. and D. Pothier. 2010. Spatiotemporal variability in tree and stand mortality caused by spruce budworm outbreaks in eastern Quebec. Can. J. Forest Res. 40: 86-94. doi: 10.1139/X09-178. Boucher, D., L. De Grandpré and S. Gauthier. 2003. Développement d'un outil de classification de la structure des peuplements et comparaison de deux territoires de la pessière à mousses du Québec. Forest. Chron. 79(2): 318-328. doi: 10.5558/tfc79318-2.

Boucher, Y., P. Grondin, and I. Auger. 2014. Land use history (1840-2005) and physiography as determinants of southern boreal forests. Landscape Ecol. 29: 437-450. doi : 10.1007/s10980-013-9974-x. Cardinall, D. 2004. Ecosystem-based Management Planning Handbook. Coast Information Team, Victoria, BC.

Comité scientifique sur les enjeux de biodiversité. 2010. Enjeux de biodiversité de l'aménagement écosystémique dans la réserve faunique des Laurentides. Rapport du comité scientifique, sous la direction de N. Thiffault. Ministère des Ressources naturelles et de la Faune. Québec, Québec.

Conley, A. and M.A. Moote. 2003. Evaluating collaborative natural resource management. Soc. Natur. Resour. 16(5): 371-386. doi: 10.1080/08941920390190032.

Crance, J.H. 1987. Guidelines for using the Delphi technique to develop habitat suitability index curves. U.S. Fish and Wild1ife Service. Biological Report 82(10.134).

Day, J. and M. Bobeva. 2005. A generic toolkit for the successful management of Delphi studies. The Electronic Journal of Business Research Methodology 3(2): 103-116.

De Grandpré, L., S. Gauthier, C. Allain, D. Cyr, S. Périgon, A. T. Pham, D. Boucher, J. Morissette, G. Reyes, T. Aakala and T. Kuuluvainen. 2009. Towards an ecosystem approach to managing the boreal forest in the North Shore region: disturbance regime and natural forest dynamics. In S. Gauthier, M. -A. Vaillancourt, A. Leduc, L. De Grandpré, D. Kneeshaw, H. Morin, P. Drapeau and Y. Bergeron. (eds.). Ecosystem management in the boreal forest. pp. 229-255. Presses de l’Université du Québec, Québec.

Delbecq, A.L., A. H. Van de Ven D. H. and Gustafson. 1975. Group techniques for program planning: A guide to nominal group and Delphi processes. Scott Foresman Co., Glenview, IL. [Reprinted by Green Briar Press, Middleton, WI, 1986].

Donohoe, H.M. and R. D. Needham. 2009. Moving best practice forward: Delphi characteristics, advantages, potential problems, and solutions. I. J. Tourism Res. 11: 415-437. doi: 10.1002/jtr.709.

Drescher, M., A. H. Perera, C. J. Johnson, L. J. Buse, C. A. Drew and M. A. Burgman. 2013. Toward rigorous use of expert knowledge in ecological research. Ecosphere 4(7): 1-26.

Emerson, P. 2013. The original Borda count and partial voting. Soc. Choice Welf. 40(2): 353-358. doi: 10.1007/s00355-011-0603-9.

Endter-Wada, J., D. Blahna, R. Krannich and M. Brunson. 1998. A framework for understanding social science contribution to ecosystem management. Ecol. Appl. 8(3): 891-904. doi: 10.2307/ 2641275.

Frame, T. M., T. Gunton and J. C. Day. 2004. The role of collaboration in environmental management: an evaluation of land and resource planning in British Columbia. J. Environ. Plann. Man. 47(1): 59-82. doi: 10.1080/0964056042000189808.

Frewer, L.J., A. R. H. Fischer, M. T. A. Wentholt, H. J. P. Marvin, B. W. Ooms, D. Coles and G. Rowe. 2011. The use of Delphi methodology in agrifood policy development: Some lessons learned. Technol. Forecast. Soc. 78(9): 1514-1525. doi: 10.1016/j.techfore.2011.05.005. 
Garrod, B. and A. Fyall. 2004. Revisiting Delphi: the Delphi technique in tourism research. In B. W. Ritchie, P. Burns and C. Palmer. (eds.). Tourism research methods: Integrating theory with practice. pp. 85-98. CAB International, Wallingford, UK.

Gauthier, S., M. -A. Vaillancourt, D. Kneeshaw, P. Drapeau, L. De Grandpré, Y. Claveau and D. Paré. 2009. Forest ecosystem management: origins and foundations. In S. Gauthier, M. -A. Vaillancourt, A. Leduc, L. De Grandpré, D. Kneeshaw, H. Morin, P. Drapeau and Y. Bergeron. (eds.). pp. 13-37. Ecosystem management in the boreal forest. Presses de l'Université du Québec, Québec.

Grenon, F., S. Côté and C. Patry. 2010. Élaboration d'une démarche de mise en œuvre de l'aménagement écosystémique des forêts du Québec. Rapport présenté au Ministère du Développement économique, de l'Innovation et de l'Exportation. CERFO, Québec.

Grumbine, R.E. 1994. What is ecosystem management? Conserv. Biol. 8(1): 27-38. doi: 10.1046/j.1523-1739.1994.08010027.x

Hasson, F. and S. Keeney. 2011. Enhancing rigour in the Delphi technique research. Technol. Forecast. Soc. 78: 1695-1704. doi: 10.1016/j.techfore.2011.04.005.

Hasson, F., S. Keeney and H. McKenna. 2000. Research guidelines for the Delphi survey technique. J. Adv. Nurs. 32(4): 1008-1015. doi: 10.1046/j.1365-2648.2000.t01-1-01567.x.

Hess, G.R. and T. J. King. 2002. Planning open spaces for wildlife. I. Selecting focal species using a Delphi survey approach. Landscape Urban Plan. 58: 25-40. doi: 10.1016/S0169-2046(01)00230-4.

Hussler, C., P. Muller and P. Rondé. 2011. Is diversity in Delphi panelist groups useful? Evidence from a French forecasting exercise on the future of nuclear energy. Technol. Forecast. Soc. 78(9): 1642-1653. doi: 10.1016/j.techfore.2011.07.008.

Kaynak, E., J. Bloom and M. Leibold. 1994. Using the Delphi technique to predict future tourism potential. Market. Intell. Plann. 12(7): 18-29. doi: http://dx.doi.org/10.1108/02634509410065537.

Keeney, S., F. Hasson and H. McKenna. 2006. Consulting the oracle: Ten lessons from using the Delphi technique in nursing research. J. Adv. Nurs. Res. 53(2): 205-212. doi: 10.1111/j.1365-2648. 2006.03716.x.

Khadka, C. and H. Vacik. 2012. Comparing a top-down and bottom-up approach in the identification of criteria and indicators for sustainable community forest management in Nepal. Forestry 85(1): 145-158. doi: 10.1093/forestry/cpr068.

Linstone, H.A. and M. Turoff. 2002. Introduction. In H.A. Linstone and M. Turoff. (eds.). The Delphi method. Techniques and applications. pp. 3-12. New Jersey Institute of Technology, Newark, NJ.

Lozano, L. M., E. García-Cueto and J. Muñiz. 2008. Effect of the number of response categories on the reliability and validity of rating scales. Methodology 4(2): 73-79. doi: 10.1027/1614-2241.4.2.73. MacMillan, D.C. and K. Marshall. 2005. The Delphi process - an expert-based approach to ecological modelling in data-poor environments. Anim. Conserv. 9: 11-19. doi: 10.1111/j.1469-1795. 2005.00001.x.

Martino, J.P. 1993. Technological forecasting for decision making. $3^{\text {rd }}$ edition. McGraw-Hill, Inc., New York.

Masse, S., P.P. Marchand and M. Bernier-Cardou. 2014. Forecasting the deployment of short-rotation intensive culture of willow or hybrid poplar: Insights from a Delphi study. Can. J. For. Res. 44: 422-431. doi: dx.doi.org/10.1139/cjfr-2013-0364.

McFadzean, E. 2002. Developing and supporting creative problem solving teams: Part 2 - facilitator competencies. Manage. Decis. 40 (6): 537-551. doi: 10.1108/00251740210433936.

McFadzean, E. and T. Nelson. 1998. Facilitating problem-solving groups: A conceptual model. Leadership Org. Dev. J. 19(1): 6-13. doi : 10.1108/01437739810368785.

Meyer, M.A. and J. M. Booker. 2001. Eliciting and analyzing expert judgment: A practical guide. ASA-SIAM Series on Statistics and Applied Probability. Philadelphia, PA.
Mukherjee, N., J. Hugé, W. J. Sutherland, J. McNeill, M. Van Opstal, F. Dahdouh-Guebas and N. Koedam. 2015. The Delphi technique in ecology and biological conservation: Applications and guidelines. Methods Ecol. Evol. 6(9): 1097-1109. doi: 10.1111/2041210X.12387.

Mullen, P. M. 2003. Delphi: myths and reality. J. Health Organ. Manag. 17(1): 37-52. doi: 10.1108/14777260310469319.

Novakowski, N. and B. Wellar. 2008. Using the Delphi technique in normative planning research: Methodological design considerations. Environ. Plann. A 40: 1485-1500. doi: 10.1068/a39267.

Okoli, C. and S. D. Pawlowski. 2004. The Delphi method as a research tool: An example, design considerations and applications. Inform. Manage. 42: 15-29. doi: 10.1016/j.im.2003.11.002.

Oliver, I. 2002. An expert panel-based approach to the assessment of vegetation condition within the context of biodiversity conservation. Stage 1: the identification of condition indicators. Ecol. Indic. 2: 223-237. doi: 10.1016/S1470-160X(02)00025-0.

Robinson, K. A., C. R. Dennison, D. M. Wayman, P. J. Pronovost and D. M. Needham. 2007. Systematic review identifies number of strategies important for retaining study participants. J. Clin. Epidemiol. 60(8): 757-765. doi: 10.1016/j.jclinepi.2006.11.023.

Rowe, G. and G. Wright. 1996. The impact of task characteristics on the performance of structured group forecasting techniques. Int. J. Forecasting 12: 73-89. doi:10.1016/0169-2070(95)00658-3.

Rowe, G. and G. Wright. 1999. The Delphi technique as a forecasting tool: Issues and analysis. Int. J. Forecasting 15: 353-375. doi: 10.1016/S0169-2070(99)00018-7.

Rowe, G. and G. Wright. 2001. Expert opinions in forecasting: the role of the Delphi technique.

In J. S. Armstrong. (ed.). Principles of forecasting. A handbook for researchers and practitioners. pp. 125-144. Springer Science + Businedd Media, New York.

Saucier, J.P., A. Robitaille and P. Grondin. 2009. Cadre bioclimatique du Québec. pp. 186-205. In R. Doucet and M. Côté (eds.). Manuel de foresterie, $2^{\text {nd }}$ edition. Ordre de ingénieurs forestiers du Québec, Éditions Multimondes, Québec, Qc.

Schmidt, R., K. Lyytinen, M. Keil and P. Cule. 2001. Identifying software project risks: An international Delphi study. J. Manage. Inform. Syst. 17(4): 5-36. doi: 10.1080/07421222.2001.11045662.

Schuster, E.G., S. S. Frissell, E. E. Baker and R. S. Loveless Jr. 1985. The Delphi method: Application to elk habitat quality. USDA, Forest Service, Intermountain Research Station, Ogden, UT. General Technical Report INT-353.

Thiffault, N., Watt, S., Leblanc, M. and Jetté, J.-P. 2007. Adaptive forest management in Quebec: Bits of the big and small picture. Canadian Silviculture May: 26-29.

Turoff, M. 2002. The policy Delphi. In H. A. Linstone and M. Turoff. (eds.). The Delphi method. Techniques and applications. pp. 80-96. New Jersey Institute of Technology, Newark, NJ.

von der Gracht, H.A. 2012. Consensus measurement in Delphi studies. Review and implications for future quality assurance. Technol. Forecast. Soc. 79: 1525-1536. doi: 10.1016/j.techfore. 2012.04.013.

Waldron, K., J. -C. Ruel and S. Gauthier. 2013. The effects of site characteristics on the landscape-level windthrow regime in the North Shore region of Quebec, Canada. Forestry 86(2): 159-171. doi: 10.1093/forestry/cps061.

Wyatt, S. 2008. First Nations, forest lands, and "aboriginal forestry" in Canada: From exclusion to co-management and beyond. Can. J. For. Res. 38: 171-180. doi: 10.1139/X07-214. 